\title{
The identification of added mass and aerodynamic damping using HHT method under wind action
}

\author{
SUN Xufeng ${ }^{1, a}$, HU Chao ${ }^{1, b}$
}

${ }^{1}$ College of Civil Science and Engineering, Yangzhou University, Yangzhou 225127, P. R. China

axu_feng_sun@163.com, bchaohu@yzu.edu.cn

Keywords: fluctuating wind; added mass; aerodynamic; Hilbert-Huang Transform

Abstract. For the long-span roof structures which have relatively low frequency and light mass, the vibration property under the action of fluctuating wind is significantly influenced by the added mass and aerodynamic damping. Since the influence can be reflected by the change of structural frequency and damping ratio, the problem can be classified as modal parameter identification. Based on Hilbert-Huang Transform, Empirical Mode Decomposition method is applied on the output signal after IIR band pass filter. Then the Random Decrement Technique is used synchronously on all the components of degree of freedom to obtain the free decay signal of required mode, so the frequency, damping ratio and mode shape can be identified. The results of numerical example show that this method can restrain noise effectively and extract the modal parameters accurately. Taking the Geiger type cable dome as example, the added mass and aerodynamic damping under the action of fluctuating wind was identified according to the principle of highly similar mode shape, and the change law of these two parameters was also obtained compared with still air environment.

\section{Introduction}

When the structure with low frequency vibrates, the surrounding air also moves together with it, thereby so-called added mass and aerodynamic damping will happen to the structure. In wind-induced analysis of such structures, these parameters should be considered. In still air, added mass and aerodynamic damping can be calculated by potential theory [1-3], and the results have been proved by experiment [4]. Yet under the action of fluctuating wind, these two parameters will change with the wind speed, test has to be done to reveal the rule.

Because the added mass mainly changes the natural frequency of the structure, while the aerodynamic damping changes the total damping, these two parameters can be obtained through parameter identification. Wu [5] completed wind tunnel test of the saddle-shape membrane structure with two different height-span ratio, and identified the added mass and aerodynamic damping under different speed and incident angle using Random Decrement Technique (RDT). Lu [6] studied the aerodynamic damping of flat roof model by Empirical Mode Decomposition (EMD), Hilbert Transform (HT) and RDT, considering the effect of hole on the upwind surface. Cao [7] analyzed the across-wind aerodynamic damping of square section super high architecture on the base of four parameter expression. The former studies focused on identification of natural frequency and damping ratio. Yet for long-span structures, the response under wind action is a broadband process, so for parameter identification, the similarity between initial and identified modes should also be considered. 
This paper will use HHT and RDT to identify the frequency and mode shape of multi-DOF system, and will obtain the added mass and aerodynamic damping based on the MAC value, thus the results will be more reasonable.

\section{Identification method for the added mass and aerodynamic damping}

HHT was proposed by Huang [8] in 1998, which is composed by EMD and HT, mainly focused on the handling of time history data.

Assume $x(t)$ is the response data, EMD can be used to handle it after IIR band pass filter for the $j$ th mode, where the band pass frequencies can be estimated by Fourier spectrum. Then for the $j$ th Intrinsic Mode Function (IMF) $x_{j}^{\prime}(t)$, RDT can be used to obtain the free decaying response

$$
x_{j}^{\prime \prime}(t)=B_{j} \exp \left(-\xi_{j} \omega_{j} t\right) \cos \left(\omega_{\mathrm{d} j} t+\theta_{j}\right)
$$

where $\xi_{j}$ is the damping ratio of the $j$ th mode, $\omega_{j}$ and $\omega_{\mathrm{d} j}$ are the undamped and damped natural frequency, which can be solved by HT method [9].

If the structure is an $n$ DOF system, all the DOF free decaying responses for the $j$ th mode can be retrieved from the IMFs simultaneously with reference to the $k$ th DOF. When the damping ratio is small enough, the free decaying responses for the $k$ th and $l$ th DOF are

$x_{j k}^{\prime \prime}(t)=B_{j k} \exp \left(-\xi_{j} \omega_{j} t\right) \cos \left(\omega_{\mathrm{dj}} t+\theta_{j}\right)$

and

$x_{j l}^{\prime \prime}(t)=B_{j l} \exp \left(-\xi_{j} \omega_{j} t\right) \cos \left(\omega_{\mathrm{d} j} t+\theta_{j}\right)$

So we have

$\frac{x_{j l}^{\prime \prime}(t)}{x_{j k}^{\prime \prime}(t)}=\frac{B_{j l} \exp \left(-\xi_{j} \omega_{j} t\right) \cos \left(\omega_{\mathrm{d} j} t+\theta_{j}\right)}{B_{j k} \exp \left(-\xi_{j} \omega_{j} t\right) \cos \left(\omega_{\mathrm{dj}} t+\theta_{j}\right)}=\frac{B_{j l}}{B_{j k}}$

From Eq. (4) we can conclude that the mode shape can be expressed by the ratio of the free decaying responses of the $n$ DOFs.

The similarity between two modes can be measured by Modal Assurance Creterion (MAC). When $\mathrm{MAC} \approx 1$, it indicates that the modes are essentially the same.

Then for the same mode in still air and in fluctuating wind, the added mass and the aerodynamic damping ratio are

$$
\frac{\Delta m_{j}}{m_{\mathrm{s} j}}=\left(\frac{\omega_{\mathrm{s} j}}{\omega_{\mathrm{d} j}}\right)^{2}-1
$$

and

$$
\Delta \xi_{j}=\xi_{\mathrm{d} j}-\xi_{\mathrm{s} j}
$$

where $m_{\mathrm{s} j}$ and $\xi_{\mathrm{s} j}$ are the mass and damping ratio of the $j$ th mode in still air. 


\section{Numerical example}

Fig. 1 is a 2-DOF system, where $m_{1}=m_{2}=1 \mathrm{~kg}, \quad c_{1}=c_{2}=2.0 \mathrm{~N} \cdot \mathrm{s} / \mathrm{m}, \quad k_{1}=k_{2}=1000 \mathrm{~N} / \mathrm{m}$. Irrelevant white noise forces are imposed on $m_{1}$ and $m_{2}$.

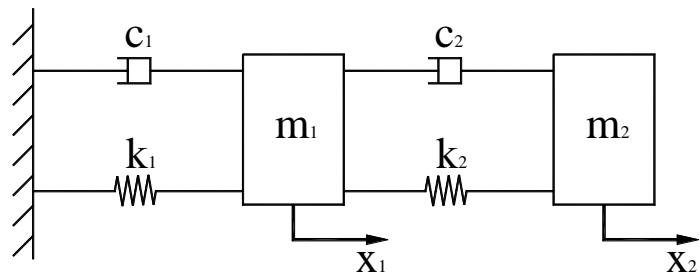

Fig. 12 DOF system

Fig. 2 is the displacement time history and spectrum, $10 \%$ noise is added on the response. From the figure we can see that the energy of the second frequency is far lower than that of the first. If EMD is imposed directly on the original signal, we can't extract the second frequency component. Yet after IIR band pass filter, the free decaying responses of 2 IMFs are successfully extracted as shown in Fig. 3, and the frequency, damping ratio, mode shape are shown in Table 1. So we can conclude that this method can be used effectively on the identification of added mass and aerodynamic damping.
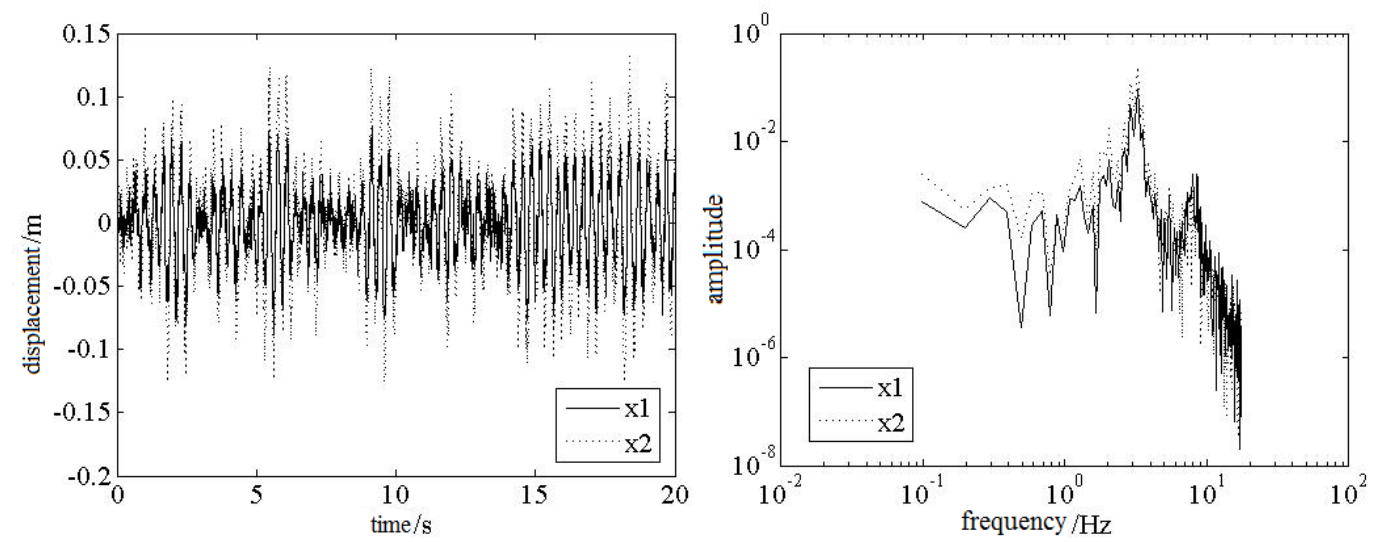

Fig. 2 Displacement and spectrum of the 2 DOF system

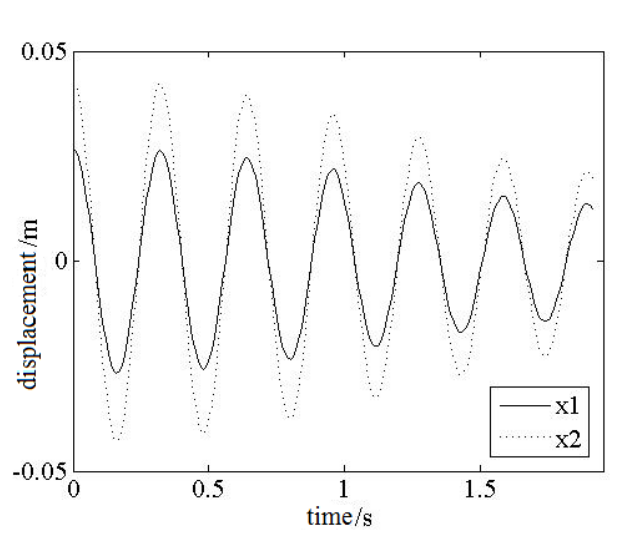

a) First component

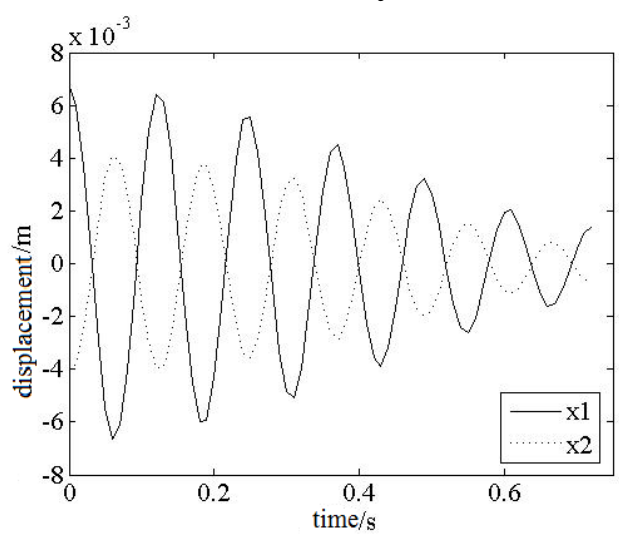

(b) Second component

Fig. 3 RD signal 


\section{Experiment on the cable dome model}

Fig. 4 shows the wind tunnel test for a cable dome model. The first natural frequency in still air is $7.29 \mathrm{~Hz}$, and damping ratio is $2.76 \%$ 。 Accelerometers are mounted on point 1 and 2, wind speed is $3 \mathrm{~m} / \mathrm{s} 、 5 \mathrm{~m} / \mathrm{s} 、 8 \mathrm{~m} / \mathrm{s}$ and $10 \mathrm{~m} / \mathrm{s}$ respectively.

Table 1 Identification results of the 2 DOF system

\begin{tabular}{ccccccc}
\hline \multirow{3}{*}{ Mode } & \multicolumn{3}{c}{ First } \\
& $\begin{array}{c}\text { Frequency } \\
{[\mathrm{Hz}]}\end{array}$ & $\begin{array}{c}\text { Damping } \\
\text { ratio [\%] }\end{array}$ & $\begin{array}{c}\text { Mode shape } \\
\left(\mathrm{x}_{1}: \mathrm{x}_{2}\right)\end{array}$ & $\begin{array}{c}\text { Frequency } \\
{[\mathrm{Hz}]}\end{array}$ & $\begin{array}{c}\text { Second } \\
\text { ratio [\%] }\end{array}$ & $\begin{array}{c}\text { Mode shape } \\
\left(\mathrm{x}_{1}: \mathrm{x}_{2}\right)\end{array}$ \\
\hline $\begin{array}{c}\text { Identification } \\
\text { Theory }\end{array}$ & 3.12 & 1.90 & $1: 1.610$ & 8.11 & 5.01 & $1:-0.611$ \\
\hline
\end{tabular}
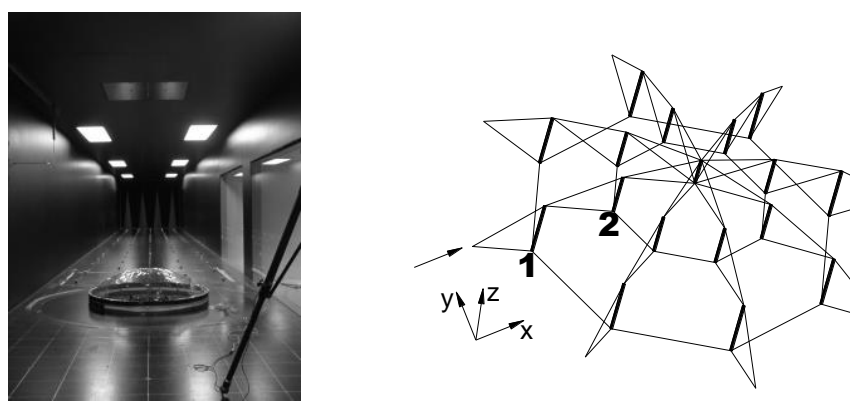

Fig. 4 Wind tunnel test of the cable dome model

Fig. 5 is the welch spectrum of point 2 along y direction. Distilling the mode parameters for the marked frequencies in Fig. 5, we can obtain the MAC values as shown in Table 2. Based on the facts that the first mode of the cable dome is anti-symmetry, the 6 DOFs of point 1 and 2 can be used to identify the first mode.

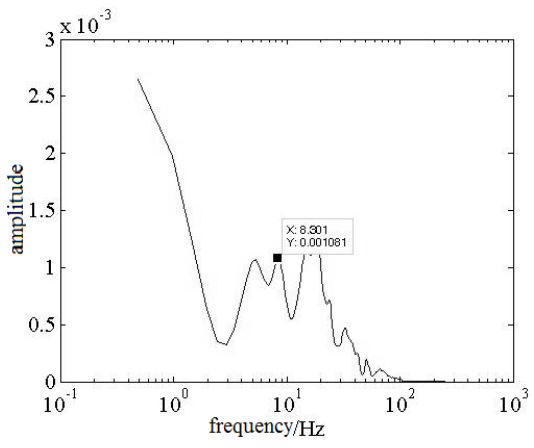

a) $3 \mathrm{~m} / \mathrm{s}$

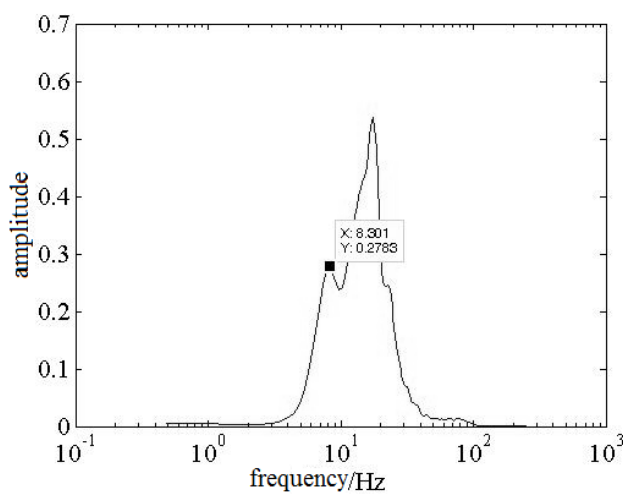

c) $8 \mathrm{~m} / \mathrm{s}$

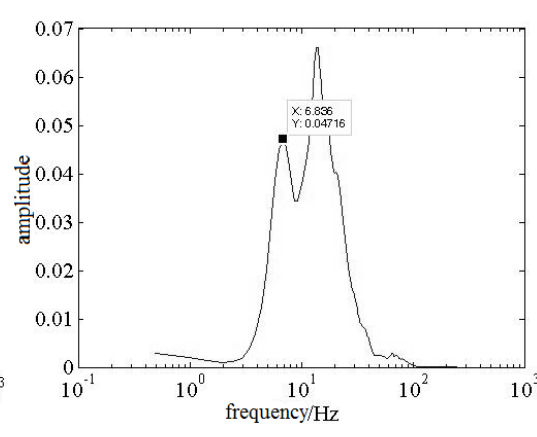

b) $5 \mathrm{~m} / \mathrm{s}$

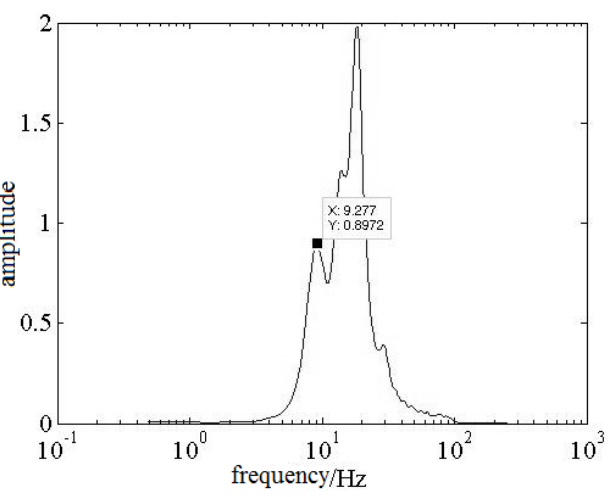

d) $10 \mathrm{~m} / \mathrm{s}$

Fig. 5 The spectrum of point 2 along y direction 
Table 2 Identified MAC vale

\begin{tabular}{cccccc}
\hline $\begin{array}{c}\text { Wind speed } \\
{[\mathrm{m} / \mathrm{s}]}\end{array}$ & 0 & 3 & 5 & 8 & 10 \\
\hline 0 & 1.000 & 0.902 & 0.965 & 0.941 & 0.983 \\
3 & 0.902 & 1.000 & 0.928 & 0.935 & 0.916 \\
5 & 0.965 & 0.928 & 1.000 & 0.985 & 0.988 \\
8 & 0.941 & 0.935 & 0.985 & 1.000 & 0.980 \\
10 & 0.983 & 0.916 & 0.916 & 0.980 & 1.000 \\
\hline
\end{tabular}

Note: '0' indicate the still air.

Based on Eq. (5) and Eq. (6), the identified added mass and aerodynamic damping ratio are shown in Table 3. So we can see that, compared to the results in still air, these two parameters will rise with the wind speed, then will decline after reaching the maximum value. This changing law is consistent with article [10], and that about the aerodynamic damping also meshes with article [11].

Table 3 Identification results for the added mass and aerodynamic damping

\begin{tabular}{cccccc}
\hline $\begin{array}{c}\text { Wind speed } \\
{[\mathrm{m} / \mathrm{s}]}\end{array}$ & 0 & 3 & 5 & 8 & 10 \\
\hline $\begin{array}{c}\text { Frequency [Hz] } \\
\text { Damping ratio }\end{array}$ & 7.29 & 8.39 & 6.75 & 8.39 & 9.26 \\
$\quad 2 \%]$ & 2.76 & 3.71 & 4.37 & 1.87 & 1.51 \\
$\begin{array}{l}\text { Added mass [\%] } \\
\text { Aerodynamic } \\
\text { damping ratio }\end{array}$ & - & -24.5 & +16.6 & -24.5 & -38.0 \\
$\quad-$ & +0.95 & +1.61 & -0.89 & -1.25 \\
\hline Note: '0' indicate the still air. & & & &
\end{tabular}

\section{Conclusions}

Compared to still air environment, the parameter identification for fluctuating wind is far more complex. Till now, the studies generally didn't consider the mode shape similarity between different wind speed conditions. Based on HHT and RD technique, this paper proposed a kind of identification method considering the MAC value, thereby obtain the added mass and aerodynamic damping. Numerical and experiment results indicate that

1) IIR band pass filter can effectively restrain the noise, and can accurately retrieve the needed mode signal. For the IMFs of all DOF, simultaneous RDT can exactly identify the frequency, damping ratio and mode shape of all components.

2) The experiment results show that, compared with still air environment, the added mass and aerodynamic damping will rise with wind speed, and then decline after reaching some maximum value.

\section{Acknowledgements}

This work was financially supported by the Chinese National Natural Science Foundation (51378451). 


\section{References}

[1] H. Minami: Added mass of a membrane vibrating at finite amplitude. Journal of Fluids and Structures, Vol. 12 (1998), p. 919-932.

[2] Q. Zhou, P. F. Joseph: A numerical method for the calculation of dynamic response and acoustic radiation from an underwater structure. Journal of Sound and Vibration, Vol. 283 (2005), p. 853-873.

[3] X. F. Sun, S. L. Dong: Numerical analysis of added mass arising from fluid flow induced by vibration of three-dimensional structure. Engineering Mechanics, Vol. 25(7) (2008), p. 1-4 (In Chinese).

[4] Y. Q. Li, L. Wang, Z. Y. Shen, Y. Tamura: Added-mass estimation of flat membranes vibrating in still air. Journal of Wind Engineering and Industrial Aerodynamics, Vol. 99 (2011), p. 815-824.

[5] Y. Wu, Q. S. Yang, S. Z. Shen: Wind tunnel tests on aeroelastic effect of wind-induced vibration of tension structures. Engineering Mechanics, Vol. 25(1) (2008), p. 8-15 (In Chinese).

[6] D. Lu, W. J. Lou, Y. Yang: Numerical calculation on wind-induced damping of membrane structure based on fluid-structure interaction. Journal of Vibration and Shock, Vol. 32(6) (2013), p. 47-53 (In Chinese).

[7] H. L. Cao, Y. Quan, M. Gu: Experimental study on across-wind aerodynamic damping of square super-high-rise building. China Civil Engineering Journal, Vol. 46(4) (2013), p. 18-25 (In Chinese).

[8] N. E. Huang, Z. Shen, S. R. Long. The empirical mode decomposition and hilbert spectrum for nonlinear and nonstationary time series analysis[J]. Proceedings of the Royal Society A: Mathematical, Physical and Engineering Sciences, 1998, 454: 903-995.

[9] G. H. James, T. G. Carne, J. P. Lauffer. The natural excitation technique(NExT) for modal parameter extraction from operating structures[J]. International Journal of Analytical and Experimental Modal Analysis, 1995, 10(4): 260-277.

[10] X. Y. Sun, in: Study on wind-structure interaction in wind-induced vibration of membrane structure. Harbin Institute of Technology, 2007 (In Chinese).

[11] R. E. R. Aquino, Y. Tamura. Framework for structural damping predictor models based on stick-slip mechanism for use in wind-resistant design of buildings[J]. Journal of Wind Engineering and Industrial Aerodynamics, 2013, 117: 25-37. 